\title{
Electrical Conductivity, Magnetoconductivity and Dielectric Behaviour of (Mg,Ni)-Ferrite below Room Temperature
}

\author{
Somenath Ghatak ${ }^{1}$, Ajit Kumar Meikap ${ }^{1}$, Manika Sinha ${ }^{2}$, Swapan Kumar Pradhan ${ }^{2}$ \\ ${ }^{1}$ Department of Physics, National Institute of Technology, Deemed University, Durgapur, India; ${ }^{2}$ Department of Physics, University \\ of Burdwan, Burdwan, India. \\ Email: meikapnitd@yahoo.com
}

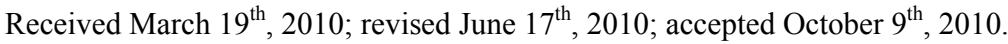

\begin{abstract}
We report a comprehensive study of electrical transport properties of stoichiometric $(\mathrm{Mg}, \mathrm{Ni})$-ferrite in the temperature range $77 \leq T \leq 300 \mathrm{~K}$, applying magnetic field upto $1 \mathrm{~T}$ in the frequency range $20 \mathrm{~Hz}-1 \mathrm{MHz}$. After ball milling of $\mathrm{MgO}$, $\mathrm{NiO}$ and $\alpha-\mathrm{Fe}_{2} \mathrm{O}_{3}$ and annealing at $1473 \mathrm{~K}, a(\mathrm{Mg}, \mathrm{Ni})$-ferrite phase is obtained. The temperature dependency of dc resistivity indicates the prevalence of a simple hopping type charge transport in all the investigated samples. The activation energy decreases by annealing the samples by $1473 \mathrm{~K}$. The dc magnetoresistivity of the samples is positive, which has been explained by using wave function shrinkage model. The frequency dependence of conductivity has been described by power law and the frequency exponent 's' is found to be anomalous temperature dependent for ball milling and annealing samples. The real part of the dielectric permittivity at a fixed frequency was found to follow the power law $\varepsilon(f, T) \propto T^{n}$. The magnitude of the temperature exponent ' $n$ ' strongly depends on milling time and also on annealing temperature. The dielectric permittivity increases with milling and also with annealing. An analysis of the complex impedance by an ideal equivalent circuit indicates that the grain boundary contribution is dominating over the grain contribution in conduction process.
\end{abstract}

Keywords: Ferrites, Chemical Synthesis, X-Ray Scattering, Transport Properties

\section{Introduction}

Small ferri-magnetic oxides, technically known as ferrites have attracted considerable attention not only from a fundamental scientific interest but also from a practical point of view for growing applications in the magnetic, electronic and microwave fields [1-7]. Simultaneous presence of magnetic and dielectric nature of ferrites is vastly exploited in a variety of applications at different frequencies. The special feature of these materials is that the properties can be tailored over wide ranges by appropriate substitution of various ions in the chemical formula unit and control of processing procedures. Ferrites are extensively used in magnetic recording, information storage, colour imaging, bio-processing, magnetic refrigeration and in magneto optical devices [5-7]. Ferrites also have great promise for atomic engineering of materials with functional magnetic properties. The formation of corrosion product on the out of core surfaces in pressurized heavy water reactors (PHWRs) are major problem.
Ferrite having spinal structure such as magnetic and nickel etc play a major role to prevent such problem. Thus attempts are being made to study the various ferrites to evaluate the impact of substitution of the divalent metal ions to modify the properties of these oxides.

Spinals are characterized by a very compact oxygen array with cations in tetrahedral (A) and octahedral (B) coordination and may be described by the ${ }^{\mathrm{IV}}\left(\mathrm{A}_{1-\mathrm{i}} \mathrm{B}_{\mathrm{i}}\right)$ ${ }^{\mathrm{VI}}\left(\mathrm{B}_{2-\mathrm{i}} \mathrm{A}_{\mathrm{i}}\right) \mathrm{O}_{4}$ structural formula, where IV and VI represent tetrahedrally and octahedrally coordinated sites, A and $B$ are cations with variable valency and $i$ the inversion parameter. Normal spinal are those with $i=0$, inverse spinals those with $i=1$.

Different synthetic roots are employed in preparation of ferrites [8-10]. High energy ball milling is a very suitable solid state processing technique for the preparation of nanocrystalline ferrite powder exhibiting new and unusual properties [11-14]. The objectives of the present work are 1) to prepare the $\mathrm{Mg}-\mathrm{Ni}$ ferrite by ball milling 
the stoichiometric mixture of $\mathrm{MgO}, \mathrm{NiO}$ and $\alpha-\mathrm{Fe}_{2} \mathrm{O}_{3}$ and 2) to study the anomalous transport properties of ballmilled and post-annealed samples below room temperature.

\section{Experimental}

$\mathrm{MgO}, \mathrm{NiO}$ and $\alpha-\mathrm{Fe}_{2} \mathrm{O}_{3}$ powders were taken in 0.25: 0.25: $0.5 \mathrm{~mol} \%$ respectively and were hand-ground by an agate mortar pestle in a doubly distilled acetone medium for more than $5 \mathrm{~h}$. The dried homogeneous powder mixture was then termed as unmilled stoichiometric homogeneous powder mixture. A part of this mixture was ball milled at room temperature in air in a planetary ball mill (Model P5, M/S Fritsch, GmbH, Germany) with hardened chrome steel vial of volume $80 \mathrm{ml}$ using 30 hardened chrome steel ball of $10 \mathrm{~mm}$ diameter, at ball to powder mass ratio $40: 1$ up to $20 \mathrm{~h}$. Some of the selected ball milled samples ( $8 \mathrm{~h}$ and $20 \mathrm{~h}$ ) were post annealed at $1473 \mathrm{~K}$ each for $1 \mathrm{~h}$ duration in a programmable furnace. The X-ray diffraction (XRD) patterns of the unmilled, ball milled and post annealed powders were recorded (step size $=0.02^{0} 2 \theta$, counting time $=5 \mathrm{sec}$, angular range $=15-80^{\circ} 2 \theta$ ) using $\mathrm{Ni}$-filtered $\mathrm{CuK}_{\alpha}$ radiation from a highly stabilized and automated Philips generator (PW1830) operated at $40 \mathrm{KV}$ and $20 \mathrm{~mA}$. The generator is coupled with a Philips X-ray powder diffractometer consisting of a PW $3710 \mathrm{mpd}$ controller, PW1050/37 goniometer and a proportional counter. The Rietveld's analysis based on structure and microstructure refinement of XRD data [15-19] is adopted in the present case for microstructure characterization and phase transformation kinetics of ferrite phase in the course of milling and post annealing the ball-milled powder mixture.

The electrical conductivity of the samples was measured by a standard four probe method by using $8^{1} / 2$-digit Agilent 3458 multimeter and 6514 Keithley Electrometer. The ac measurement was carried out with a 4284A Agilent Impedance analyzer up to the frequency $1 \mathrm{MHz}$ at different temperatures. Liquid nitrogen cryostat was used to study the temperature dependent conductivity by the ITC 502S Oxford temperature controller. To measure the ac response, samples were prepared as $1 \mathrm{~cm}$ dia pellets by pressing the powder under a hydraulic pressure of $500 \mathrm{MPa}$. The density of the pressed pellets were in the range $3.74 \mathrm{~g} / \mathrm{cc}$ to $5.89 \mathrm{~g} / \mathrm{cc}$. Fine copper wires were used as the connecting wire and silver paint was used as coating materials. The capacitance $\left(C_{P}\right)$ and the dissipation factor $(D)$ were measured at various frequencies and temperatures. The real part of ac conductivity and real and imaginary part of dielectric permittivity have been calculated using the relations $\sigma^{\prime}(f)=2 \pi \varepsilon_{\varepsilon_{0}} \varepsilon^{\prime \prime}(f), \varepsilon(f)=$ $C_{P} d / \varepsilon_{0} A$ and $\varepsilon^{\prime \prime}(f)=\varepsilon^{\prime}(f) D$ respectively, where $\varepsilon_{0}=8.854$ $\times 10^{-12} \mathrm{~F} / \mathrm{m}, A$ and $d$ are the area and thickness of the sample respectively. $C_{P}$ is the capacitance measured in farad; $f$ is the frequency in Hz. The magnetoconductivity was measured in the same manner varying the transverse magnetic field $\mathrm{B} \leq 1 \mathrm{~T}$ by using an electromagnet.

\section{Results and Discussion}

Figure 1 shows the recorded XRD patterns of unmilled $(0 \mathrm{~h})$ and ball milled mixture of $\mathrm{MgO}, \mathrm{NiO}$ and $\alpha-\mathrm{Fe}_{2} \mathrm{O}_{3}$ powders for different durations of milling. The powder pattern of unmilled $(0 \mathrm{~h})$ mixture contains only the individual reflections of $\mathrm{MgO}, \mathrm{NiO}$ and $\alpha-\mathrm{Fe}_{2} \mathrm{O}_{3}$ phases. The intensity ratios of individual reflections are in accordance with the stoichiometric composition of the mixture. After $3 \mathrm{~h}$ of milling, the particle size of all phases reduces considerably which is evident from the broadened reflections of all phases. There is no clear evidence of ferrite phase formation in $3 \mathrm{~h}$ ball milled sample as all intense reflections of ferrite phase are overlapped with broadened reflections of starting phases. But the intensity ratios of the starting phases were changed after $3 \mathrm{~h}$ of milling and a careful observation of the reflection at $2 \theta=35.42^{\circ}$ clearly reveals the fact that the (110) reflection of $\alpha-\mathrm{Fe}_{2} \mathrm{O}_{3}$ phase stands out as the most strongest reflection. This significant change in intensity indicates the formation of the ferrite phase which has its most intense (311) peak at $2 \theta$ $=35.715^{\circ}$. Intensities of $\mathrm{MgO}$ reflections show quite a large value in ball milled samples up to $20 \mathrm{~h}$ milling and $\mathrm{MgO}$ phase stands out as the major phase in the course of milling. This increment of $\mathrm{MgO}$ phase may be attributed to the formation of $\mathrm{MgO}-\mathrm{NiO}$ solid solution [20] as both

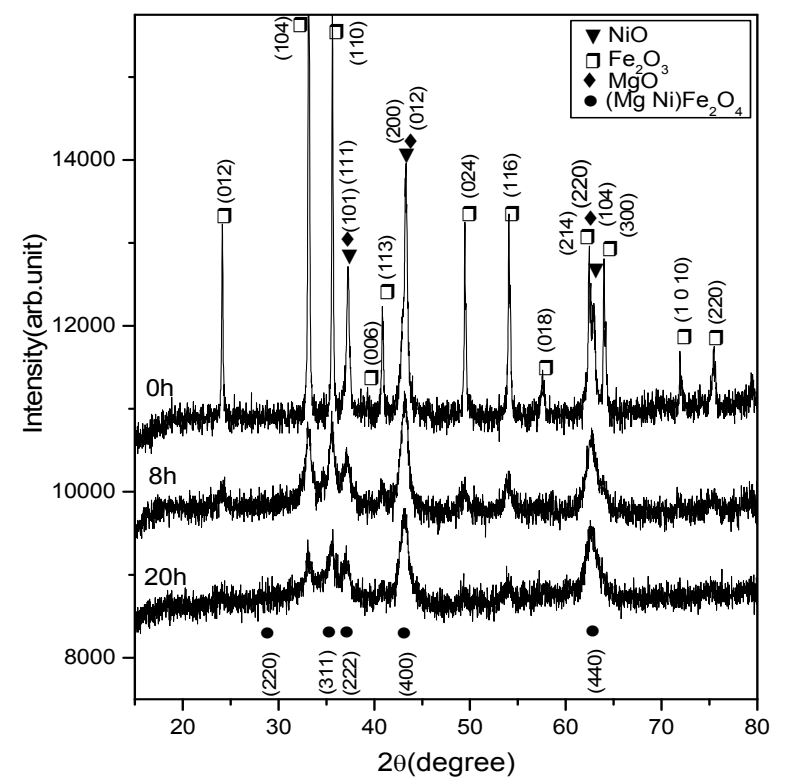

Figure 1. X-ray diffraction patterns of unmilled and ball milled stoichiometric mixture of $\mathrm{MgO}, \mathrm{NiO}$ and $\alpha-\mathrm{Fe}_{2} \mathrm{O}_{3}$ powders. 
the phases have same crystal structure (MgO; cubic, space group $\mathrm{Fm} \overline{3} \mathrm{~m}$ (ICDD PDF \# 87-0653) and NiO; cubic, space group $\mathrm{Fm} \overline{3} \mathrm{~m}$ (ICDD PDF \# 040835)) and radii of $\mathrm{Mg}^{+2}(0.72 \AA)$ and $\mathrm{Ni}^{+2}(0.69 \AA)$ ions are very close.

The mole fraction, lattice parameter and particle size of all phases present in the unmilled and ball milled samples with increasing milling time are given in Table 1. The mole fraction of $\alpha-\mathrm{Fe}_{2} \mathrm{O}_{3}$ phase decreases rapidly with increasing milling time and that of $\mathrm{NiO}$ phase decreases slowly. The $\mathrm{NiFe}_{2} \mathrm{O}_{4}$ phase is noticed to form after $3 \mathrm{~h}$ milling and its content increases with increasing milling time. The continuous increase of the content of $\mathrm{MgO}$ phase up to $20 \mathrm{~h}$ of milling above its starting value ( 0.25 mole fractions) indicates that $\mathrm{MgO}$ phase is not contributing in ferrite phase formation, furthermore, a part of $\mathrm{NiO}$ phase is diffused into $\mathrm{MgO}$ matrix. Therefore only a small percentage of $\mathrm{Ni}^{+2}$ ions participate in ferrite formation and the formed ferrite phase is eventually a Ni-ferrite phase. It is clearly evident from the Table 1 that the ferrite phase has formed initially with a low value of lattice parameter $(0.833 \mathrm{~nm})$ and then saturates at a value $0.840 \mathrm{~nm}$ at higher milling times. The lattice parameter of $\mathrm{MgO}$ decreases and that of $\mathrm{NiO}$ increases up to $8 \mathrm{~h}$ of milling and after that both the lattice parameter values saturate at higher milling time. The contraction of $\mathrm{MgO}$ lattice is due to the substitution of larger $\mathrm{Mg}^{+2}$ ions by smaller $\mathrm{Ni}^{+2}$ ions in the $\mathrm{MgO}$ lattice. Similarly the small increase of lattice parameter of $\mathrm{NiO}$ phase is due to the replacement of small amount of smaller $\mathrm{Ni}^{+2}$ ions by larger $\mathrm{Mg}^{+2}$ ions. After $8 \mathrm{~h}$ milling no further solid solution is formed because most part of $\mathrm{MgO}$ and $\mathrm{NiO}$ were used up in the formation of both $\mathrm{MgO}$ solid solution and ferrite phases. It is also evident from the Table 1 that the lattice parameter of the $\alpha-\mathrm{Fe}_{2} \mathrm{O}_{3}$ phase did not change appreciably with increasing milling time, indicates that both $\mathrm{MgO}$ and $\mathrm{NiO}$ phases did not diffuse into $\alpha-\mathrm{Fe}_{2} \mathrm{O}_{3}$ lattice. On other hand, all starting phases are showing a decrease in their particle size with increasing milling time. The particle size of $\alpha-\mathrm{Fe}_{2} \mathrm{O}_{3}$ phase decreases sharply from $\sim 161 \mathrm{~nm}$ to a value $\sim 17 \mathrm{~nm}$ within $3 \mathrm{~h}$ of milling time and remains almost unchanged in higher milling time. $\mathrm{NiO}$ phase also shows a considerable decrease in its particle size (from $\sim 46 \mathrm{~nm}$ to $\sim 20$ $\mathrm{nm}$ ) within $3 \mathrm{~h}$ of milling and further milling has a very slow decreasing effect on its particle size. The $\mathrm{MgO}$ phase initially has a low value of particle size $(\sim 25 \mathrm{~nm})$ in comparison to the other two starting phases and decrease in particle size of $\mathrm{MgO}$ phase is very small with increasing milling time. The ferrite phase formed with a very small particle size $(\sim 4 \mathrm{~nm})$ and with increasing milling time the size decreases very slowly and finally attains a value $\sim 3 \mathrm{~nm}$ after $20 \mathrm{~h}$ of milling.

Figure 2 shows the XRD patterns of ball milled sam- ples annealed at temperature $1473 \mathrm{~K}$. It seems that the (Mg,Ni)-ferrite phase is formed completely after this heat-treatment. However, a critical Rietveld analysis reveals the presence of a very small amount of $\mathrm{NiO}$ phase along with the ferrite phase (Table 1). It indicates that almost a stoichiometric (Mg,Ni)-ferrite phase has been obtained at $1473 \mathrm{~K}$. The Rietveld analysis also reveals that $\sim 0.92 \mathrm{~mol}$ fraction inverse spinel ferrite phase is formed both in $8 \mathrm{~h}$ and $20 \mathrm{~h}$ ball milled samples. This indicates that the amount of ferrite phase formation is independent of milling time. By measuring particle size we actually measure the coherently diffracting zone of a grain. The particle or crystallites re separated from each other by grain boundaries and the grain boundaries are nothing but bulk crystal imperfections in a crystal. The size of the crystallites in the ball milled samples is in the nanometer range. As can be seen from the experiment, annealing the sample increases the size of the particles. Heat energy helps to annihilate the deformations in the crystals. As a result of grain boundaries started to vanish during annealing and the small crystallites agglomerate together to form larger particles due to intra-grain diffusion. The experimentally observed patterns $\left(\mathrm{I}_{0}\right)$ of the annealed samples are fitted with theoretically simulated patterns $\left(I_{c}\right)$ as shown in Figure 3. The accuracy of fitting is shown by the fitting residual $\mathrm{I}_{0}-\mathrm{I}_{\mathrm{c}}$, plotted at the bottom of respective patterns.

The dc resistivity of different $(\mathrm{Mg}, \mathrm{Ni})$-ferrite samples was measured as a function of temperature. It is observed

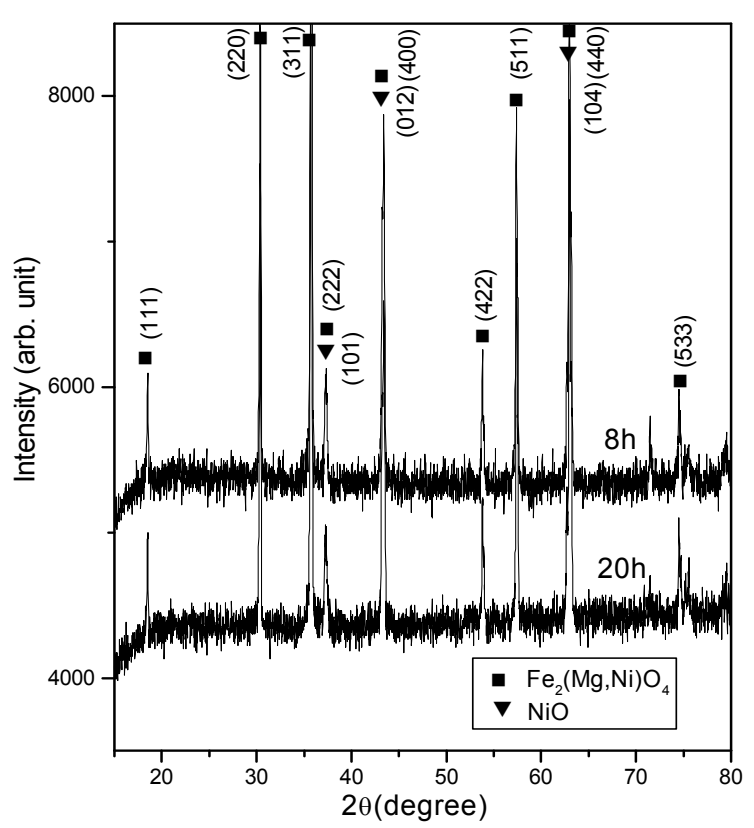

Figure 2. X-ray powder diffraction patterns of ball-milled mixtures of $\mathrm{MgO}, \mathrm{NiO}$ and $\alpha-\mathrm{Fe}_{2} \mathrm{O}_{3}$ powders annealed at temperature $1473 \mathrm{~K}$. 
Table 1. Microstructure parameters of unmilled and ball milled (Mg,Ni)-ferrite revealed by Rietveld's X-ray powder structure refinement analysis.

\begin{tabular}{|c|c|c|c|c|c|}
\hline \multirow{2}{*}{ Sample } & \multirow{2}{*}{ Phase Present } & \multirow{2}{*}{ Mole fraction } & \multicolumn{2}{|c|}{ Lattice parameter } & \multirow{2}{*}{ Particle size (nm) } \\
\hline & & & $\mathrm{a}(\mathrm{nm})$ & $\mathrm{c}(\mathrm{nm})$ & \\
\hline \multirow{3}{*}{$\begin{array}{c}\text { MNF-0 h } \\
(0 \mathrm{~h} \text { ballmilled })\end{array}$} & $\mathrm{MgO}$ & 0.2549 & 0.4212 & & 25.12 \\
\hline & $\mathrm{NiO}$ & 0.1703 & 0.4177 & & 46.72 \\
\hline & $\alpha-\mathrm{Fe}_{2} \mathrm{O}_{3}$ & 0.5747 & 0.5035 & 1.3753 & 161.47 \\
\hline \multirow{4}{*}{$\begin{array}{c}\text { MNF-3 h } \\
\text { (3 h ballmilled) }\end{array}$} & $\mathrm{MgO}$ & 0.3715 & 0.4197 & & 20.94 \\
\hline & $\mathrm{NiO}$ & 0.1102 & 0.4178 & & 20.25 \\
\hline & $\alpha-\mathrm{Fe}_{2} \mathrm{O}_{3}$ & 0.4149 & 0.5038 & 1.3758 & 17.03 \\
\hline & $\mathrm{NiFe}_{2} \mathrm{O}_{4}$ & 0.1033 & 0.8330 & & 4.44 \\
\hline \multirow{4}{*}{$\begin{array}{c}\text { MNF-8 h } \\
\text { (8 h ballmilled) }\end{array}$} & $\mathrm{MgO}$ & 0.3871 & 0.4193 & & 15.88 \\
\hline & $\mathrm{NiO}$ & 0.1103 & 0.4180 & & 15.61 \\
\hline & $\alpha-\mathrm{Fe}_{2} \mathrm{O}_{3}$ & 0.3565 & 0.5041 & 1.3761 & 16.08 \\
\hline & $\mathrm{NiFe}_{2} \mathrm{O}_{4}$ & 0.1460 & 0.8404 & & 4.99 \\
\hline \multirow{4}{*}{$\begin{array}{c}\text { MNF-20 h } \\
\text { (20 h ballmilled) }\end{array}$} & $\mathrm{MgO}$ & 0.4589 & 0.4194 & & 12.78 \\
\hline & $\mathrm{NiO}$ & 0.0402 & 0.4180 & & 12.05 \\
\hline & $\alpha-\mathrm{Fe}_{2} \mathrm{O}_{3}$ & 0.1514 & 0.5050 & 1.3733 & 15.72 \\
\hline & $\mathrm{NiFe}_{2} \mathrm{O}_{4}$ & 0.3495 & 0.8401 & & 2.71 \\
\hline \multirow{2}{*}{$\begin{array}{c}\text { MNF-8 h-1473 K } \\
\text { (8 h ballmilled \& } \\
\text { annealed at } 1473 \mathrm{~K} \text { ) }\end{array}$} & $\mathrm{Fe}_{2}(\mathrm{Mg}, \mathrm{Ni}) \mathrm{O}_{4}$ & 0.9232 & 0.8357 & & 495.49 \\
\hline & $\mathrm{NiO}$ & 0.0768 & 0.4195 & & 217.67 \\
\hline \multirow{2}{*}{$\begin{array}{c}\text { MNF-20 h-1473 K } \\
(20 \text { h ballmilled \& } \\
\text { annealed at } 1473 \mathrm{~K} \text { ) }\end{array}$} & $\mathrm{Fe}_{2}(\mathrm{Mg}, \mathrm{Ni}) \mathrm{O}_{4}$ & 0.9208 & 0.8353 & & 574.44 \\
\hline & $\mathrm{NiO}$ & 0.0792 & 0.4194 & & 211.41 \\
\hline
\end{tabular}

that resistivity decrease with increasing temperature, which suggests the semi conducting behavior of the samples. Generally in ferrite phase the conduction mechanism arises due to exchange of electrons between the ions of the same elements present in more than one valance state, more are randomly distributed over crystallographic lattices site. It is well known that in spinal ferrite $\mathrm{Ni}$ and $\mathrm{Mg}$ ions prefer to occupy ' $\mathrm{B}$ ' and 'A' sites respectively. The conductivity in $(\mathrm{Mg}, \mathrm{Ni})$-ferrite may be due to electron hopping between $\mathrm{Fe}^{+3} \leftrightarrow \mathrm{Fe}^{+2}$ and hole hopping between $\mathrm{Ni}^{+2} \leftrightarrow \mathrm{Ni}^{+3}$ at octahedral site. The decrease in resistivity with increase in temperature is due to the increase in drift mobility of the charge carriers. The temperature dependence of resistivity found to follow the Arrhenius equation,

$$
\rho(T)=\rho(0) \exp \left(\frac{E_{a}}{K_{B} T}\right)
$$

where $\rho(0)$ is the resistivity at infinite temperature, $E_{a}$ is the activation energy, $K_{B}$ is the Boltzmann constant. According to the Figure 4 the linear variation of $\ln [\rho(T)]$ with $1 / \mathrm{T}$ indicates the prevalence of a simple hopping type charge transport in all the investigated samples. The values of $E_{a}$ are obtained from the slopes of the different straight lines curves in the Figure $4(0.29 \mathrm{eV}$ for MNF-8 h, $0.13 \mathrm{eV}$ for MNF-8 h-1473 K, $0.36 \mathrm{eV}$ for MNF-20 h, $0.12 \mathrm{eV}$ for MNF-20 h-1473 K). Hence the activation energy increases by increasing milling time due to decrease of particle size. However, it is also seen that the activation energy decreases by annealing the samples by $1473 \mathrm{~K}$. This decrease of activation energy may be due to the increase of particle size where the metal core increases by vanishing the grain boundaries by annealing the samples.

The magnetic field dependent resistivity of the samples has been measured under the influence of magnetic field of strength $<1 \mathrm{~T}$. The variation of magnetoresistivity with magnetic field at $\mathrm{T}=300 \mathrm{~K}$ for different samples 


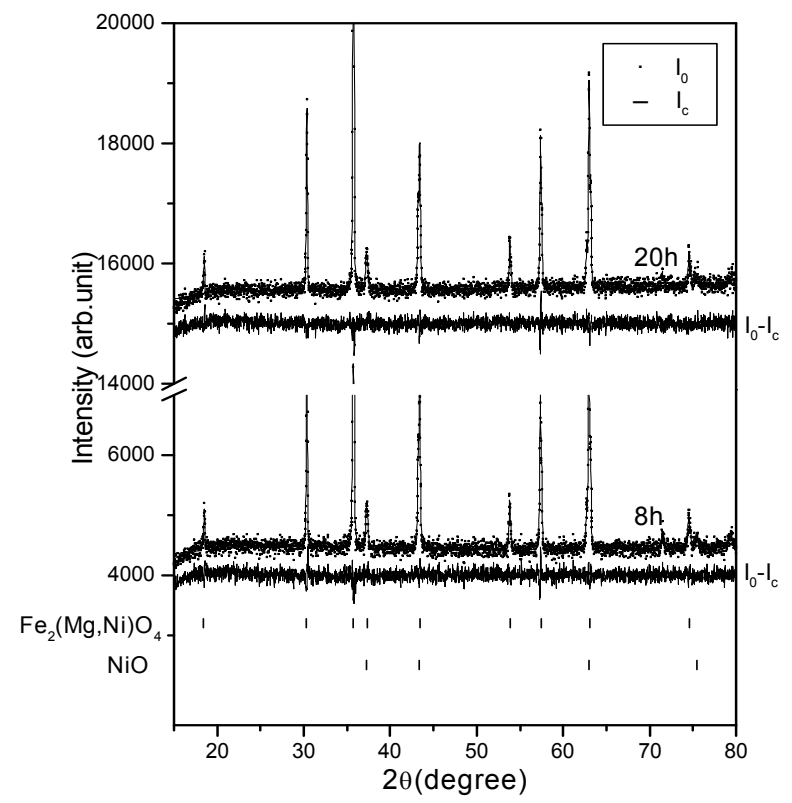

Figure 3. Observed (.) and calculated (-) X-ray powder diffraction patterns of post annealed ballmilled powder mixture of $\mathrm{MgO}, \mathrm{NiO}$ and $\alpha-\mathrm{Fe}_{2} \mathrm{O}_{3}$ revealed by Rietveld powder structure refinement analysis. Peak positions of phases present are shown at base line as small markers (I).

is shown in Figure 5. It is observed that the room temperature magnetoresistivity of all samples is positive. The magnitude of the maximum percentage change of resistivities $[\{(\rho(B, T)-\rho(0, T)) / \rho(0, T)\} \times 100]$ in the presence of magnetic field of $0.8 \mathrm{~T}$ at $300 \mathrm{~K}$ were observed about $57.4 \%$ for MNF-0 h, 24.1\% for MNF-20 h and $3.4 \%$ for MNF-20 h-1473 K. It is observed that the magnetoresistivity of the investigated samples decreases with increasing the milling time and also by annealing. The measured magnetoresistivity data could be explained by simple phenomenological model that consists of two simultaneously acting hopping processes, namely the wave function shrinkage model $[21,22]$ and the forward interference model [23-25]. The wave function shrinkage model corroborates the fact that by applying a magnetic field the wave functions of electrons are contracted and reduces the average hopping length. This corresponds to a positive magnetoresistivity (negative magnetoconductivity) i.e., resistivity increases with increasing magnetic field. On the other hand, the forward interference model takes into account the effect of forward interference among random paths in the hopping process between two sites spaced at a distance equal to the optimum hopping distance and the theory predicts the negative magnetoresistivity (positive magnetoconductivity). For the sample having small localization length, the average hopping length $R_{h o p}=(3 / 8)\left(T_{M o t t} / T\right)^{1 / 4} L_{l o c}$ is small and the wave

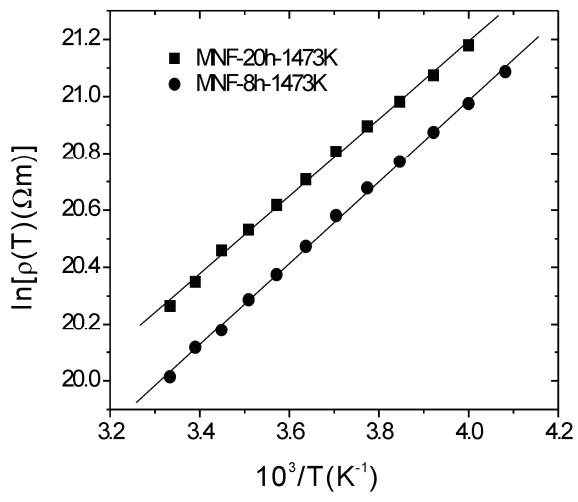

Figure 4. Temperature dependence of de resistivity of different $(\mathrm{Mg}, \mathrm{Ni})$-ferrite samples.

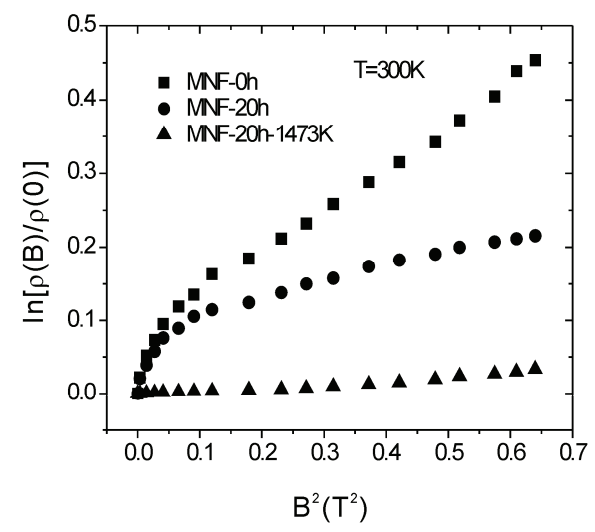

Figure 5. Variation of de magnetoconductivity with magnetic field at temperature $\mathrm{T}=300 \mathrm{~K}$ of different samples.

function shrinkage effect is dominated. But this effect is not evident in samples having large localization length, where the quantum interference effect [26,27] is dominated. Therefore, the sign and magnitude of the magnetoresistivity changes due to competition of the two (wave function shrinkage and quantum interference) types of contributions. As the magnetoresistivity ratio of the investigated samples increases with increasing magnetic field at a temperature $300 \mathrm{~K}$, we assume that the contribution due to wave function shrinkage model predominated over the quantum interference model. So, we analyzed our measured data in the light of the wave function shrinkage model. According to this model, for a small magnetic field, the magnetoconductivity ratio can be expressed by the following relationship [21]

$$
\ln \left(\frac{\rho(B, T)}{\rho(0, T)}\right)=t_{1} \frac{e^{2} L_{l o c}^{4}}{\hbar^{2}}\left(\frac{T_{\text {Mott }}}{T}\right)^{3 / 4} B^{2}
$$

where, $t_{1}=5 / 2016$ and $L_{l o c}$ is the localization length. Figure 5 shows a linear variation in the plot of $\ln$ $[\rho(B, T) / \rho(0, T)]$ versus $B^{2}$ for different samples. The 
points are the experimental data while the solid lines represent the best fits obtained on the basis of the wave function shrinkage model. It is evident from the Figure 5 that the experimental data can be well described by the theory as indicated in (2). It is observed from the fitting that the slope of the curves are 0.59 for MNF- 0 h, 0.19 for MNF-20 h and 0.07 for MNF-20 h-1473 K samples. The slope of unmilled MNF-0 h sample is much greater than the ballmilled and annealed samples. This is because in unmilled sample, the individual phases of oxides of $\mathrm{Fe}$, $\mathrm{Ni}$ and $\mathrm{Mg}$ contribute the magnetoresistivity. However in ballmilled and annealed samples, ferrite phases exist and by milling, the particle size decreases and more disorder presents in the sample. Since, in sample with higher disorder, electronic wave functions are more localized within smaller regions resulting smaller localization length. Therefore, the lowering of slope arises due to reduction of localization length.

The ac conductivity of $\mathrm{Mg}$-Ni ferrite samples are investigated in the frequency range $20 \mathrm{~Hz}$ to $1 \mathrm{MHz}$ and in the temperature range $77 \leq \mathrm{T} \leq 300 \mathrm{~K}$. The measured data showed that the variation of conductivity with frequency at a particular temperature is prominent at higher frequencies, whereas at low frequencies it is almost independent with frequencies, this could be attributed to the dc contribution. A general feature of amorphous semiconductors or disordered systems is that the frequency dependent conductivity $\sigma_{a c}(f)$ obeys a power law with frequency. The total conductivity $\sigma(f)$ at a particular temperature over a wide range of frequencies can be expressed as [28-30]

$$
\sigma^{\prime}(f)=\sigma_{d c}+\sigma_{a c}(f)=\sigma_{d c}+\alpha f^{s}
$$

where $\sigma_{d c}$ is the dc conductivity, $\alpha$ is the temperature dependent constant and the frequency exponent $s<1$. The value of $\sigma_{a c}(f)$ has been determined upon subtraction of the dc contribution from the total frequency dependent conductivity $\sigma(f)$. Figure 6 shows the linear variation of $\ln \left[\sigma_{a c}(f)\right]$ with $\ln (f)$ at different temperatures for the sample MNF-20 h-1473 K. Similar behavior was observed for all other samples. The value of ' $s$ ' at each temperature has been calculated from the slope of $\left.\ln \left[\sigma_{a c} f f\right)\right]$ versus $\ln (f)$ plot for each temperature. The trend of change in ' $s$ ' with temperature is shown in Figure 7 for different samples. The temperature dependency of ' $s$ ' of disordered systems has been explained by two physical processes such as correlated barrier hopping $(\mathrm{CBH})[30]$ and quantum mechanical tunneling (QMT) like electron tunneling (ET) [31], small polaron tunneling (SPT) [30] and large polaron tunneling (LPT) [29]. As the nature of temperature dependency of ' $s$ ' for different conduction processes are different, the exact nature of charge transport may be obtained experimentally from the temperature variation

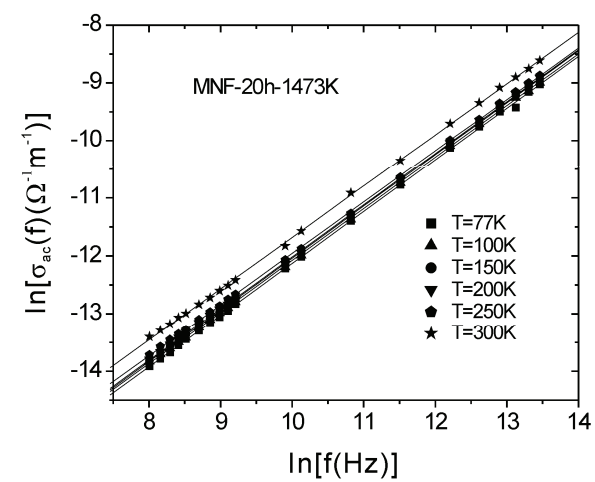

Figure 6. Frequency dependent ac conductivity at different temperatures of MNF-20 h-1473 K sample.

of the frequency exponent ' $s$ '. According to the correlated barrier hopping model ' $s$ ' increases with the decrease in temperature. From the trend of change in ' $s$ ' with temperature for unmilled sample (MNF-0 h), it is presumed that the correlated barrier hopping is suitable. According to this model, the charge carrier hops between the sites over the potential barrier separating them and the frequency exponent ' $s$ ' is given by the expression [30].

$$
s=1-\frac{6 k_{B} T}{W_{H}-k_{B} T \ln \left(\frac{1}{\omega \tau_{0}}\right)}
$$

where $W_{H}$ is the effective barrier height and $\tau_{o}$ is the characteristic relaxation time. According to (4), for large values of $W_{H} / k_{B} T$, the variation of ' $s$ ' with frequency is so small that it is effectively independent of frequency [32]. On the other hand, the linear variation of $\ln \left[\sigma_{a c}(f)\right]$ vs $\ln (f)$ in Figure 6 supports that ' $s$ ' is independent of frequency in our investigated samples. Therefore, we fitted experimental data with (4) as function of temperature alone with $W_{H}$ and $\omega \tau_{o}$ as fitting parameters. In Figure 7 the points represent the experimental data whereas solid lines are the theoretical best fit values obtained from (4) for MNF-0 h sample and the best fitted values of the parameters $W_{H}$ and $\tau_{o}$ (at a fixed frequency of $f=$ $10 \mathrm{KHz}$ ) are $1.16 \mathrm{eV}$ and $5.97 \times 10^{-13} \mathrm{~S}$. The value of $W_{H}$ are, as expected, higher than the activation energy measured from dc contribution and the values of the characteristic relaxation time $\tau_{o}$ are comparable with those that would be expected for typical inverse phonon frequency. Therefore, it may be concluded that the ac conductivity of MNF-0 h sample can be described by CBH model. But for MNF-20 h sample, ' $s$ ' has to increase first upto $\mathrm{T}<150 \mathrm{~K}$ and then decrease with further increasing of temperature $(\mathrm{T}>150 \mathrm{~K})$. Similar trend was observed in annealed (MNF-20 h-1473 K) sample with weaker temperature dependency. Hence, the anomalous behavior 


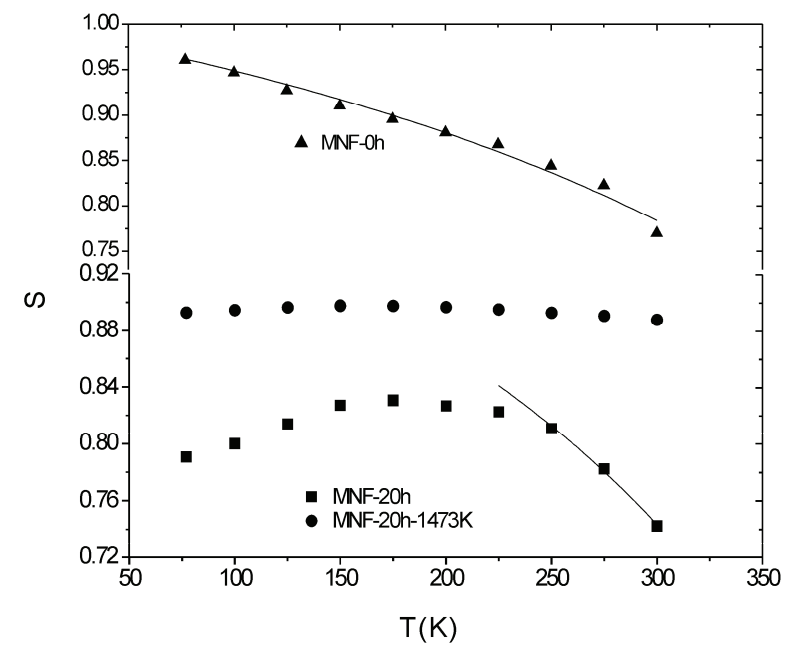

Figure 7. Variation of frequency exponent ' $s$ ' with temperature of different samples.

of ' $s$ ' with temperature $(\mathrm{T}<150 \mathrm{~K})$ for MNF-20 $\mathrm{h}$ and MNF-20 h-1473 K cannot be understood completely with $\mathrm{CBH}$ model and indicates the another mechanism of transport for carriers in these investigated systems. However, according to small polaron tunneling ' $s$ ' only increases with increasing temperature. We try to fit the experimental data for $\mathrm{T}<150 \mathrm{~K}$ with the small polaron tunneling (SPT) theory [30], but the fit yields the unphysical values of the parameters. So the temperature dependence of ' $s$ ' is in conflict with SPT theory. To have a clear concept of this, we plotted the variation of $\sigma(f)$ with temperature for MNF-20 h-1473 K sample in the Figure 8. At a particular frequency the real part of complex conductivity increases with temperature and is found to follow a power law $\sigma(f) \propto T^{n}$, which are shown as the solid lines in Figure 8. The values of $n$ have been calculated from the power law fitting and found to be strongly frequency dependent. With increasing frequency from $1 \mathrm{KHz}$ to $1 \mathrm{MHz}$ the values of ' $n$ ' decreases from 10.1 to 7.3 for MNF-20 $\mathrm{h}$ and 9.5 to 7.2 for MNF-20 h-1473 K. According to the CBH model [30] the ac conductivity $\sigma^{d}(f)$ is expressed as $\sigma^{d}(f) \propto T^{2} R_{\omega}^{6} \cong T^{n}$ with $n=$ $2+(1-s) \ln \left(1 / \omega \tau_{0}\right)$ for broad band limit and $\sigma^{\prime}(f) \propto R_{\omega}^{6} \cong$ $T^{n}$ with $n=(1-s) \ln \left(1 / \omega \tau_{o}\right)$ for narrow band limit, where $R_{\omega}=e^{2} /\left\{\pi \varepsilon \varepsilon_{o}\left[W_{H}-k_{B} T \ln \left(1 / \omega \tau_{o}\right)\right]\right\}$. We have calculated theoretically the values of ' $n$ ', taking $\tau_{o}=4.34 \times 10^{-14} \mathrm{~s}$ and the value of $s=0.74$ for $300 \mathrm{~K}$ and 0.79 for $77 \mathrm{~K}$ for MNF-20 h sample. With increasing frequency from 1 $\mathrm{KHz}$ to $1 \mathrm{MHz}$, the calculated values of ' $n$ ' varies 7.73 to 5.93 for $300 \mathrm{~K}$ and 6.63 to 5.17 for $77 \mathrm{~K}$ for broad band limit and 5.7 to 3.9 for $300 \mathrm{~K}$ and 4.6 to 3.2 for $77 \mathrm{~K}$ for narrow band limit. The experimental values did not match with the theoretical values, this indicates that both the broad band and narrow band are not suitable for ex-

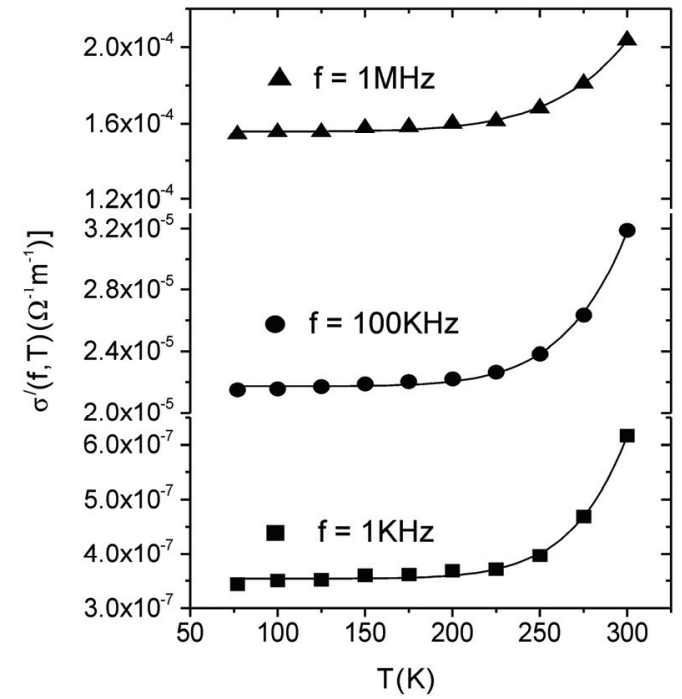

Figure 8. AC conductivity as a function of temperature at different frequencies of MNF-20 h-1473 K sample.

plaining the temperature dependency of ac conductivity. Therefore, this observation cannot be understood completely in terms of the existing theory of charge transport. Anyway, more studies are necessary to formulate the true mechanism and this experimental result may add impetus to the theoretical community to rethink this issue.

The variation of real part of dielectric permittivity $\varepsilon(f, T)$ with temperature is shown in Figure 9 for different samples at $f=1 \mathrm{MHz}$. In the $\varepsilon-T$ plot there is no sharp peak till the temperature is raised to $300 \mathrm{~K}$, which is the maximum temperature employed in our investigation. At a particular frequency the real part of dielectric permittivity increases with temperature and is found to follow a power law $\varepsilon(f) \propto T^{n}$, which are shown as the solid lines in Figure 9. The values of $\mathrm{n}$ have been calculated from the power law fitting and found that its value is strongly dependent on milling time and also on annealing temperature. Generally the ferrite exhibits interfacial polarization due to structural inhomogeneities and existence of free charges [33]. It is thought that the hopping electrons at low frequencies may be trapped by the inhomogeneities. The increase of $\varepsilon(f)$ with temperature at a particular frequency is due to the drop in the resistance of the ferrite with increasing temperature. The low resistance promotes electron hopping, hence resulting in a larger polarizability or larger $\varepsilon(f)$. The frequency dependence of real part of the dielectric permittivity $\varepsilon(f)$ have also been studied for different samples and shown in Figure 10 for $\mathrm{T}=300 \mathrm{~K}$ and in Figure 11 for MNF$20 \mathrm{~h}-1473 \mathrm{~K}$ sample at different yet constant temperatures. A weak variation is noticed in the dielectric pemittivity at lower temperature, although a large variation of the same is observable at higher temperature for all the samples. 


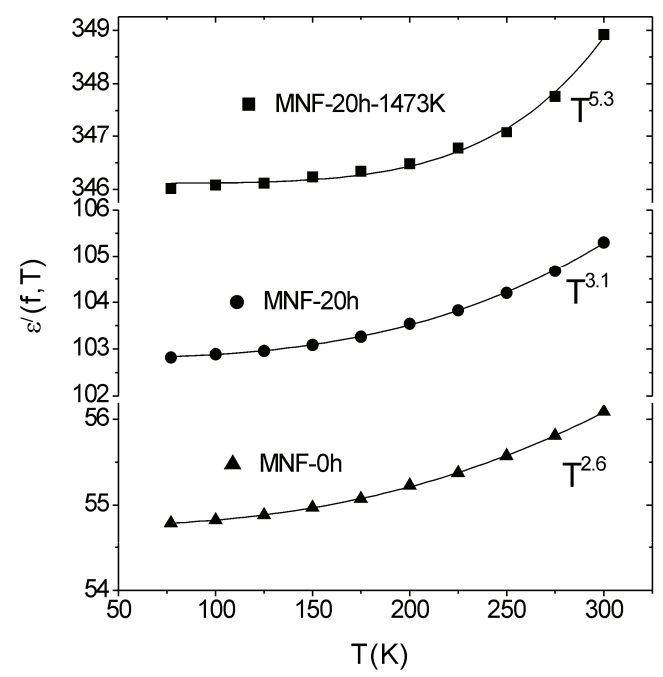

Figure 9. Thermal variation of dielectric constant of different samples at $1 \mathrm{MHz}$ frequency.

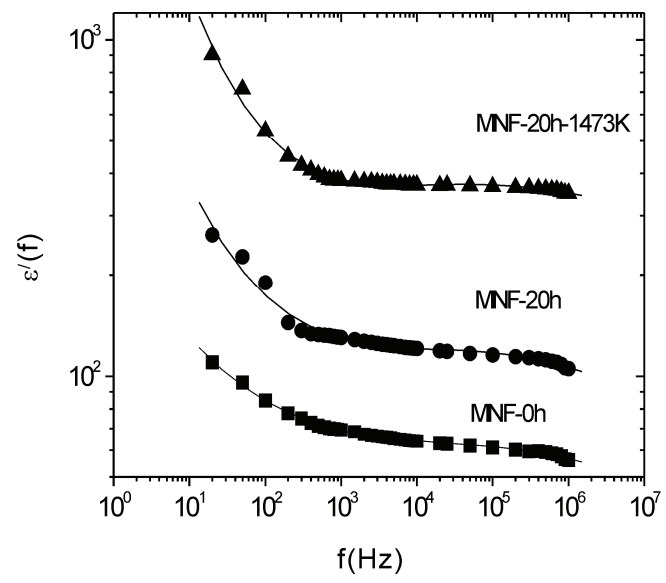

Figure 10. Variation of dielectric constant as function of frequency at $\mathrm{T}=\mathbf{3 0 0} \mathrm{K}$ for different samples.

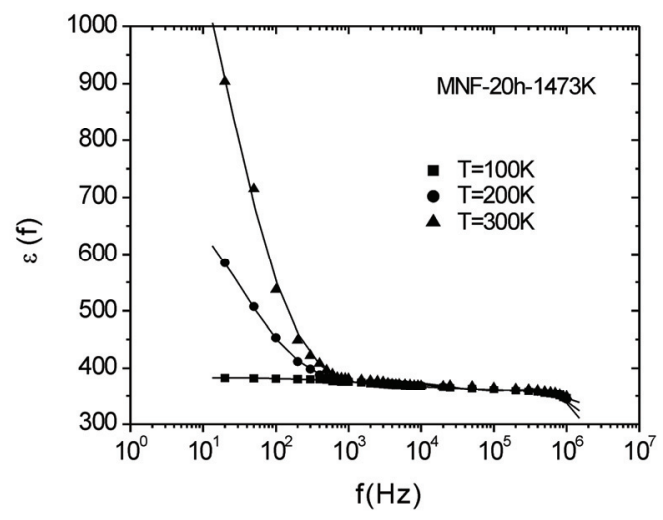

Figure 11. Variation of dielectric constant as function of frequency at different temperatures of MNF-20 h-1473 K sample.
At a fixed temperature, the dielectric pemittivity $\varepsilon(f)$ increase sharply with decreasing frequency and this sharp increase shifts to lower frequencies as the temperature is reduced. Such sudden increase of real part of the dielectric constant $\varepsilon(f)$ at low frequency can be attributed to the presence of large degree of dispersion due to charge transfer within the interfacial diffusion layer present between the electrodes. The magnitude of the dielectric dispersion is temperature dependent. At lower temperature, the freezing of the electric dipoles through the relaxation process is easier. So there exists decay in polarization with respect to the applied electric field, which is evidenced by the sharp decrease in $\varepsilon^{\prime}(f)$ at lower frequency region. When the temperature is high, the rate of polarization formed is quick and thus the relaxation occurs in high frequency. Due to this, the position of the sharp increase shifts towards higher frequency by increasing temperature. Therefore, the frequency behavior of $\varepsilon(f)$ is due to inhomogeneous nature (containing different permittivity and conductivity regions) of the samples, where the charge carriers are blocked by poorly conducting region. The effective dielectric permittivity of such inhomogeneous systems is given by Maxwell Wagner capacitor model [34-35]. The complex impedance of such systems can also be modeled by an ideal equivalent circuit consisting of resistance and capacitance due to grain and interfacial grain boundary contribution and it can be expressed as

$$
\begin{gathered}
Z=\frac{1}{i \omega C_{0} \varepsilon(\omega)}=Z^{\prime}-i Z^{\prime \prime} \\
Z^{\prime}=\frac{R_{g}}{1+\left(\omega R_{g} C_{g}\right)^{2}}+\frac{R_{g b}}{1+\left(\omega R_{g b} C_{g b}\right)^{2}} \\
Z^{\prime \prime}=\frac{\omega R_{g}^{2} C_{g}}{1+\left(\omega R_{g} C_{g}\right)^{2}}+\frac{\omega R_{g b}^{2} C_{g b}}{1+\left(\omega R_{g b} C_{g b}\right)^{2}}
\end{gathered}
$$

where sub indexes ' $g$ ' and ' $g b$ ' refer to the grain and interfacial grain boundary respectively, $R=$ resistance, $C=$ capacitance, $\omega=2 \pi f$ and $C_{0}=$ free space capacitance. The real part of the complex impedance have been calculated from the experimental data for real $\left(\varepsilon^{\prime}\right)$ and imaginary $\left(\varepsilon^{d /}\right)$ part of the dielectric permittivity by using the relation $Z^{\prime}(f)=\varepsilon^{\prime \prime}(f) /\left[\omega C_{0}\left(\varepsilon(f)^{2}+\varepsilon^{\prime \prime}(f)^{2}\right)\right]$ for different samples and analyzed by (6). Figure 12 shows the frequency dependence of the real part of the complex impedance at room temperatures for different samples. The points are the experimental data and the solid lines are the theoretical values obtained from (6). The grain and grain boundary resistances and capacitances have been extracted from this analysis at room temperature, whose values lie within the range 25 to $87 \mathrm{~K} \Omega$ for $R_{g}, 0.5$ 


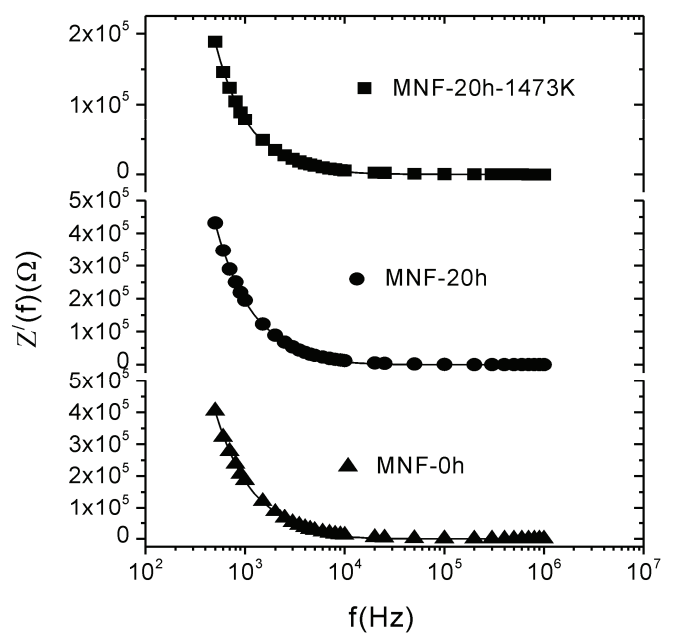

Figure 12. The real part of the complex impedance versus frequency at $\mathrm{T}=300 \mathrm{~K}$ of different samples.

to $1.02 \mathrm{M} \Omega$ for $R_{g b}, 0.63$ to $1.56 \mathrm{nF}$ for $C_{g}$ and 0.43 to $0.92 \mathrm{nF}$ for $C_{g b}$ for different samples. It is observed from the Figure 12 that the experimental data are reasonably well fitted with the theory. It is observed that the grain capacitance $\left(C_{b}\right)$ are comparable with the grain boundary capacitance $\left(C_{g b}\right)$ for the investigated samples. However, the resistance due to interfacial grain boundary is much larger in compare to the grain resistance. This implies that the grain boundary contribution dominates over the grain contribution. Since the ferrites are semiconductors, the conduction process can be explained by hopping mechanism, where the carrier mobility is dominated by a factor that increases with temperature exponentially. This temperature dependent factor is controlled by thermal activation in order to overcome the potential barrier between the sites by hopping.

\section{Conclusions}

The above experimental observations suggest the following facts: 1) A Ni-ferrite phase and $\mathrm{MgO}-\mathrm{NiO}$ solid solution is obtained in ball milling the powder mixtures of $\mathrm{MgO}, \mathrm{NiO}$ and $\alpha-\mathrm{Fe}_{2} \mathrm{O}_{3} ; 2$ ) Ni-ferrite phase is obtained in the ball milling process is a non-stoichiometric phase with a number of cation vacancies; 3) Particle size of Ni-ferrite phase reduces to $\sim 3 \mathrm{~nm}$ within $20 \mathrm{~h}$ of milling; 4) After annealing at $1473 \mathrm{~K}, \sim 0.92 \mathrm{~mol}$ fraction of $(\mathrm{Mg}, \mathrm{Ni})$-ferrite phase is obtained. The dc resistivity decreases with increasing temperature and the same follows a hopping type charge transport. The magnetoresistivity is positive and its magnitude reduces with increasing the milling time and also by annealing and it can be explained by the wave function shrinkage model. The real part of the complex ac conductivity was found to follow the power law $\sigma^{\prime}(f) \propto T^{p} f^{s}$. The magnitude of the temperature exponent ' $p$ ' strongly depends on frequency and its value decreases with increasing frequency. A detailed analysis of the temperature dependence of the universal dielectric response parameter ' $s$ ' revealed that the correlated barrier hopping is the dominating charge transport mechanism for only unmilled sample, however, anomalous temperature dependency has been observed for ball milling and annealing samples, which cannot be explained in terms of existing theory of charge transport. Anyway, more studies are necessary to formulate the true mechanism and this experimental result may add impetus to the theoretical community to think about this issue. At a particular frequency the real part of the dielectric permittivity was found to follow the relation $\varepsilon(f, T) \propto T^{n}$. The magnitude of the temperature exponent ' $n$ ' strongly depends on milling time and also on annealing temperature. The frequency dependent real part of the dielectric permittivity shows large degree of dispersion at low frequency, but rapid polarization at high frequencies, which can be interpreted by Maxwell-Wagner capacitor model. The complex impedance of such systems can also be modelled by an ideal equivalent circuit consisting of resistance and capacitance due to grain and interfacial grain boundary contribution. The details analysis of this indicates that the grain and grain boundary capacitances are comparable with each other; however, the resistance due to interfacial grain boundary is much larger in compare to the grain resistance.

\section{Acknowledgements}

This work has been carried out under Grant nos. F.27-1/ 2002. TS.V dated 19.03.2002 and F.28-1/2003.TS.V dated 31-03.2003 sanctioned by the MHRD, Government of India. The authors gratefully acknowledge the principal assistance received from the above organization during this work.

\section{REFERENCES}

[1] I. Anton., I. D. Dabata and L. Vekas, "Application Orientated Researches on Magnetic Fluids," Journal of Magnetism and Magnetic Materials, Vol. 85, No. 1-3, 1990, pp. 219-226.

[2] R. D. McMickael, R. D. Shull, L. J. Swartzendruber, L. H. Bennett and R. E. Watson, "Magnetocaloric Effect in Superparamagnets," Journal of Magnetism and Magnetic Materials, Vol. 111, No. 1-2, 1992, pp. 29-33.

[3] D. L. Leslie-Pelecky and R. D. Rieke," Magnetic Properties of Nanostructures Materials," Chemistry of Materials, Vol. 8, No. 8, 1996, pp. 1770-1783.

[4] T. Hirai, J. Kobayashi and I. Koasawa, "Preparation of Acicular Ferrite Fine Particles Using an Emulsion Liquid 
Membrane System," Langmuir, Vol. 15, No. 19, 1999, pp. 6291-6298.

[5] R. H. Kodama, "Magnetic Nanoparticles," Journal of Magnetism and Magnetic Materials, Vol. 200, No. 1-3, 1999, pp. 359-372.

[6] K. V. P. M. Shafi, Y. Koltypin, A. Gedanken, R. Prozorov, J. Balogh, J. Lendvai and I. Felner, "Sonochemical Preparation of Nanosized Amorphous $\mathrm{NiFe}_{2} \mathrm{O}_{4}$ Particles," The Journal of Physical Chemistry B, Vol. 101, No. 33, 1996, pp. 6409-6414.

[7] D. Niznansky, M. Drillon and J. L. Renspinger, "Preparation of Magnetic Nanoparticles $\left(\gamma-\mathrm{Fe}_{2} \mathrm{O}_{3}\right)$ in the Silica Matrix," IEEE Transaction on Magnetics, Vol. 30, No. 2, 1994, pp. 821-823.

[8] J. M. Yang, W. J. Tsuo and F. S. J. Yen, "Preparation of Ultrafine Nickel Ferrite Powder Using Ni and Fe Tartrates," Journal of Solid State Chemistry, Vol. 145, No. 1, 1999, pp. 50-57.

[9] Y. Shi, J. Ding, X. Liu and J. Wang, " $\mathrm{NiFe}_{2} \mathrm{O}_{4}$ Ultrafine Particles Prepared by Co-Precipitation/Mechanical Alloying," Journal of Magnetism and Magnetic Materials, Vol. 205, No. 2-3, 1999, pp. 249-254.

[10] P. Druska, U. Steinike and V. Sepelak, "Surface Structure of Mechanically Activated and of Mechanosynthesized Zinc Ferrite," Journal of Solid State Chemistry, Vol. 146, No. 1, 1999, pp. 13-21.

[11] V. Sepelak, K. Tkacova, V. V. Boldyrev and U. Steinike, "Crystal Srtucture Refinement of the Mechanically Activated Spinel-Ferrite," Materials Science Forum, Vol. 228-231, 1996, pp. 783-788.

[12] V. Sepelak, A. Yu, U. Rogachev, D. Steinike, C. Uecker, S. Wibmann and K. D. Becker, "Structure of Nanocrystalline Spinel Ferrite Produced by High Energy Ballmilling Method," Acta Crystallographica A, Vol. A 52, No. (Suppl.), 1996, p. C367

[13] V. Sepelak, A. Yu, U. Rogachev, D. Steinike, C. Uecker, F. Krumcich, S .Wibmann and K. D. Becker, "The Synthesis and Structure of Nanocrystalline Spinel Ferrite Produced by High Energy Ball-Milling Method," Materials Science Forum, Vol. 235-238, 1997, pp. 139-144.

[14] V. Sepelak, U. Steinike, D. C. Uecker, S. Wibmann and K. D. Becker, "Structural Disorder in Mechanosynthesized by Zinc Ferrite," Journal of Solid State Chemistry, Vol. 135, No. 1, 1998, pp. 52-58.

[15] H. M. Rietveld, "Line Profile of Neutron Powder Diffraction Peaks for Structure Refinement," Acta Crystallographica, Vol. 22, 1967, pp. 151-152.

[16] H. M. Rietveld, "A Profile Refinement Method for Nuclear and Magnetic Structures," Journal of Applied Crystallography, Vol. 2, 1969, pp. 65-71.

[17] R. A. Young, "The Rietveld Method," Oxford University Press, Oxford, 1996.

[18] L. Lutterotti, P. Scardi and P. Maistrelli, "LSI-a Computer Program for Simultaneous Refinement of Material Structure and Microstructure," Journal of Applied Crystallography, Vol. 25, No. 3, 1992, pp. 459-462.
[19] L. Lutterotti, "MAUD Version 2.046." http://www.ing. unitn. it/ luttero/maud

[20] W. D. Kingery, H. K. Bowen and D. R. Uhlmann, "Introduction to Ceramics," 2nd Edition, John Wiley and Sons, New York, 1976.

[21] B. I. Shklovskii, "Positive Magnetoresistance in the Variable Range Hopping Conduction Regimes," Soviet Physics Semiconductors, Vol. 17, 1983, p. 1311.

[22] B. I. Shklovskii and A. L. Efros, "Electronic Properties of Doped Semiconductors," Springer, Berlin, 1994.

[23] V. L. Nguyen, B. Z. Spivak and B. I. Shklovskii, "Tunnel Hops in Disordered Systems," Soviet Physics-JETP, Vol. 62, 1985, p. 1021

[24] U. Sivan, O. Entin-Wohiman and O. Imry, "Orbital Magnetoconduction in the Variable-Range-Hopping Regime," Physical Review Letters, Vol. 60, No. 15, 1988, pp. 1566-1569.

[25] R. Rosenbaum, A. Milner, S. Hannens, T. Murphy, E. Palm and B. Brandt, "Magnetoresistance of an Insulating Amorphous Nickel-Silicon Film in Large Magnetic Fields," Physica B, Vol. 294-295, 2001, pp. 340-346.

[26] M. S. Fuhrer, W. Holmes, P. L. Richards, P. Delaney, S. G. Louie and A. Zettl, "Nonlinear Transport and Localization in Single Walled Carbon Nanotubes," Synthetic Metals, Vol. 103, No. 1-3, 1999, pp. 2529-2532.

[27] Y. Yosida and I. Oguro, "Variable Range Hopping Conduction in Bulk Samples Composed of Single Walled Carbon Nanotubes," Journal of Applied Physics, Vol. 86, No. 2, 1999, pp. 999-1003.

[28] N. F. Mott and E. Davis, "Electronic Process in Noncrystalline Materials," 2nd Edition, Clarendon, Clarendo, 1997.

[29] A. R. Long, "Frequency-Dependent Lossin Amorphous Semi-Conductors," Advances in Physics, Vol. 31, No. 5, 1982, pp. 553-637.

[30] S. R. Elliott, "a.c. Conduction in Amorphous Chalcogenide and Pnictide Semiconductors," Advances in Physics, Vol. 36, No. 2, 1987, pp. 135-217.

[31] A. L. Efros, "On the Theory of a.c. Conduction in Amorphous Semiconductors and Chalcogenide Glasses," Philosophical Magazine B, Vol. 43, No. 5, 1981, pp. 829-838.

[32] M. Ghosh, A. Barman, S. K. De and S. Chatterjee, "Transport Properties of Hcl Doped Polyaniline and Polyaniline-Methyl Cellulose Dispersion," Journal of Applied Physics, Vol. 84, No. 2, 1998, pp. 806-811.

[33] B. G. Soares, M. E. Leyva, G. M. O. Barra and D. Khastgir, "Dielectric Behaviour of Polyaniline Synthesized by Different Techniques," European Polymer Journal, Vol. 42, No. 3, 2006, pp. 676-686.

[34] S. S. Suryavanshi, S. R. Patil, S. A. Patil and S. R. Sawant, "d.c. Conductivity and Dielectric Behaviour of $\mathrm{Ti}^{4+}$ Substituted Mg-Zn Ferrites," Journal of the Less-Common Metals, Vol. 168, No. 2, 1991, pp. 169-174..

[35] J. C. Maxwell, "A Treatise on Electricity and Magnetism," Vol. 1, Oxford University Press, Oxford, 1988. 